\title{
Semblanzas deportivas: humor, deporte y terror en Fontanarrosa
}

\author{
Cristian Palacios
}

Este artículo analiza el uso del humor negro del caricaturista Fontanarrosa en su serie Semblanzas Deportivas, definiendo, a la vez que deslindando, lo humorístico y lo cómico. Se aborda también el lugar que ocupa la obra de Fontanarrosa en la cultura popular, en donde destacan sobre todo temas deportivos como: fútbol, boxeo, atletismo y lucha libre. Se observa el uso de la literatura borgeana en Fontanarrosa y cómo, a partir de la exageración en imágenes de los rasgos de sus personajes, se consigue elaborar una crítica sin que sea necesario recurrir a la abierta oposición.

PALABRAS CLAVE: Semblanzas Deportivas, humor negro, cultura popular, deporte, lo cómico vs. lo humorístico.

This paper discusses cartoonist Fontanarrosa's use of black humor in his series Semblanzas Deportivas. We aim to define and also to demarcate humor and comedy. We also address the place of Fontanarrosa's work in popular culture, especially in regard to sports such as football, boxing, athletics and wrestling. The use of Borges' literature in Fontanarrosa is observed and we show how the exaggeration of certain features in his characters achieve criticism without having to resort to outright opposition.

KEYWORDS: Semblanzas sports, black humor, popular culture, sports, comic vs. the humorous.

Fecha de recepción: 9 de septiembre de 2013

Fecha de aceptación: 29 de noviembre de 2013 

Cristian Palacios

Universidad de Buenos Aires

\section{Semblanzas deportivas: humor, deporte y terror en Fontanarrosa}

\section{Introducción}

Lo que primero podría llamar la atención de un autor de la popularidad que ha llegado a alcanzar Fontanarrosa, es lo que en él resulta menos popular: un humor negro que sin dudas podríamos calificar como inclemente. Y aunque a lo largo de los años, con el crecimiento de su lugar como humorista insoslayable, gracias en parte, a su trabajo diario en Clarín y semanal en Viva! la revista del mismo diario, la virulencia de sus chistes se haya ido sosegando, nadie puede olvidar que otra gran parte de su fama se la debe a Boogie el aceitoso, segundo en popularidad después de Inodoro Pereyra. Y en Boogie la violencia no tiene riendas.

Deberíamos agregar además que en Boogie se encuentra gran parte de su mejor producción; junto con el primer período de Inodoro Pereyra, es decir, hasta 1976. En esas obras y en las historietas publicadas en Fierro, algunas de las cuales constituyeron series (nombraremos dos: la que nos ocupa y Sperman, el hombre del sexo de hierro) que fueron posteriormente compiladas en libros.

Una de esas series, Semblanzas Deportivas, es la que da título a este trabajo. En rigor, lo que intentaremos hacer aquí es trazar un mapa que nos permita a través de otros textos, de Fontanarrosa y de algunos otros autores, entender un poco mejor el modo en que "lo popular" aparece problematizado en estas semblanzas de Fontanarrosa, de la mano 
del deporte y por medio del humor negro, esa dimensión inquietante y fascinante a la vez de las culturas contemporáneas que es, según el punto de vista que aquí empleo, el caso paradigmático del humor. Pero intentar comprender el humor, es quizás, una contradictio in adjecto, o - como ha dicho Chesterton - constituye la prueba irrefutable de que uno carece de humor o - como ha anotado Jardiel Poncela - es como intentar pinchar una mariposa con un poste de telégrafo. En este trabajo - como en otros - intentaremos sacarle punta al poste de telégrafo para no aplastar la mariposa en el intento. Aunque con el humor nunca se sabe: puede también que el poste resulte demasiado pequeño.

La otra problemática que nos ocupará durante las páginas siguientes concierne a la ubicación de Fontanarrosa como autor popular, esta vez entendido en el sentido en el que los géneros, temáticas y problemas que aborda, son o parecen ser parte de aquello que comúnmente denominamos cultura popular: el deporte, el fútbol, una cierta construcción de la masculinidad y su contraparte, lo femenino como horizonte fascinante e inalcanzable a la vez, cierta homofobia que se desprende de los términos anteriores (véase por ejemplo El segundo sexo de Fontanarrosa) y por supuesto, el universo de lo cómico cotidiano que comprende y cristaliza en su interior todos aquellos miedos y tensiones que atraviesan una comunidad en un momento determinado.

El mismo Fontanarrosa lo ha puesto de tal modo: "De mí se dirá posiblemente que soy un escritor cómico, a lo sumo. No me interesa demasiado la definición que se haga de mí. No aspiro al Nobel de Literatura. Yo me doy por muy bien pagado cuando alguien se me acerca y me dice: 'Me cagué de risa con tu libro"' (Braceli, Fontanarrosa ...) Por eso no deja de ser significativo - como lo ha señalado Oscar Steimbergque en los homenajes posteriores a su muerte se haya hablado tanto del escritor y tan poco del historietista (Steimberg, "Ahora que pasaron: sobre los homenajes a Fontanarrosa"). Una tendencia que en sus últimos años se hacía cada vez mayor, alimentada a su vez por la tendencia del autor a trasladar el peso de sus producciones hacia lo verbal. A Fontanarrosa se lo celebrará entonces como aquel que ha sabido unir lo popular por antonomasia y lo culto por excelencia: fútbol y literatura, "cultura popular" y "cultura letrada" o "Intelectual y popular... profundo y divertido" como puntualiza en su homenaje la revista Soles Digital (entre 
otras). Polos cuyo reencuentro sólo se produce a costa del prejuicio de que alguna vez han estado separados: de que lo "profundo" no puede ser "divertido" y por lo tanto, tampoco la "cultura letrada", etc.

Lo que me parece importante señalizar aquí es que, según el punto de vista que pretendo defender, Fontanarrosa se ha vuelto más popular sólo a costa de resignar lo que en él había de más popular. Esta paradoja sólo se entiende si cambiamos el primer "popular" por "masivo" (aunque como sinónimo de esta acepción de la palabra "popular" no acaba de implicar los sentidos que ésta condensa) y el segundo por "subalterno" (en los términos puntualizados en Spivak, "Can the subaltern speak?"). Dicho en otras palabras, sobre todo a partir de los años noventa, en lo que respecta exclusivamente a su dimensión de humorista gráfico, la obra de Fontanarrosa se vuelca casi exclusivamente hacia lo que he llamado el discurso cómico, por contraposición al humorístico que podría caracterizar su obra temprana, incluida la serie que aquí nos ocupa.

\section{Breves consideraciones sobre el humor y lo cómico}

Lo cómico difiere de lo humorístico en un aspecto fundamental: mientras que el primero toma el discurso hegemónico para burlarse de él, pero sólo a expensas de reconocer ante todo la legitimidad de la hegemonía de tal discurso; el segundo opera de manera inversa. Lo cómico se burla de la Ley, pero reconoce la existencia de la ley y reconoce que además es Ley. Lo cómico, en el fondo, es resignado. Lo humorístico es opositor, porque aparenta reconocer la ley y servirse de ella, cuando en realidad opera señalando la inevitable contingencia de toda Ley. Lo cómico coloca al mundo patas para arriba, invierte los términos de las ecuaciones imaginarias de la cultura: el loco es el cuerdo, el mentiroso dice la verdad. Lo humorístico demuestra que no hay ni arriba ni abajo y que los pilares del mundo echan sus raíces en el aire.

Así sucede por ejemplo con relación a los estereotipos que configuran el imaginario del gaucho, que se traduce en los años noventa en el "prototipo" del "argentino medio" ("Chanta y antihéroe: 'un argentino común”" según se lee en el Prólogo a 20 años con Inodoro Pereyra). El Inodoro de las últimas dos décadas convoca todos aquellos estereo- 
tipos y prejuicios, y aunque se ríe de ellos, en esa misma operación, acaba por legitimarlos. De allí que pueda decirse que Inodoro es "tan argentino como la birome y el dulce de leche" o que "se convirtió en un 'argentino común', que ve transcurrir la actualidad con un asombro que se acerca al desconcierto". En contraste, el Inodoro que se publica en Hortensia en los años setenta, parece asumir la posición contraria. Así ocurre en dos capítulos paradigmáticos: "De los deberes" (publicado en el núm. 30 de Hortensia) y “¿Dónde vas, gringo?” (publicado en el núm. 48 de Hortensia). En el primero Eulogia (que recibirá luego todos los epítetos concebibles que le caben a la mujer argentina de clase media baja, según el imaginario masculino), se niega a ser adjetivada por Inodoro, el hombre que la ha raptado. En el segundo es Inodoro mismo quien soporta con gesto estoico las palabras que un grupo de turistas, presumiblemente norteamericanos, emiten sobre él. En ambos se pone en juego el discurso del poder sobre esos otros, la mujer y el gaucho, y en ambos la reacción de los personajes es magistral: con un simple y llano gesto silencioso (gesto que en el humor escénico se reconoce como la "mirada a público" del payaso) los refutan sin poner nada a cambio en su lugar.

Lo que haré a continuación, entonces, es un recorrido por algunos textos, de Fontanarrosa y de otros autores, para arribar a la serie que nos ocupa, donde creo reconocer una operación humorística similar: un cierto horror a lo popular que lejos de desmentir aquellos discursos que sobre la violencia o sobre lo sangriento de algunos deportes como el boxeo o las corridas de toros se emiten desde los medios, los toma como propios y los hiperboliza hasta lo absurdo desmontándolos, entonces, desde su núcleo mismo.

\section{Jugar a ser el otro}

El primer texto pertenece a Borges y su presencia aquí, que podría resultar sorprendente, requiere de algunas explicaciones. El texto se titula "Anotación al 23 de agosto de 1944" y fue publicado por primera vez en el número 120 de Sur, poco después del acontecimiento al que la fecha alude: la liberación de París por parte de las tropas aliadas. En 
él Borges presenta un corolario de una de las ideas más fecundas de su producción: aquella que plasma en la "Historia del guerrero y la cautiva" o en la "Biografía de Tadeo Isidoro Cruz". A saber: el desmontaje de la pareja Civilización y Barbarie, que encarna en la fascinación por las culturas subalternas; el gaucho, el bárbaro, el otro. Pero en esta Anotación, ese otro aparece asimilado al nazismo. Lo temprano de la fecha no exculpa a Borges de la comparación políticamente molesta y éticamente perturbadora:

Para los europeos y americanos, hay un orden - un sólo orden - posible: el que antes llevó el nombre de Roma y que ahora es la cultura del Occidente. Ser nazi (jugar a la barbarie enérgica, jugar a ser un viking, un tártaro, un conquistador del siglo XVI, un gaucho, un piel roja) es, a la larga, una imposibilidad mental y moral. El nazismo adolece de irrealidad, como los infiernos de Erígena. Es inhabitable; los hombres sólo pueden morir por él, mentir por él, matar y ensangrentar por él. Nadie, en la soledad central de su yo, puede anhelar que triunfe.

De allí la conclusión: Hitler, como el germanófilo al que se hizo alusión poco antes, no ignora su propia monstruosidad. Secretamente quiere ser derrotado. Asimilar "nazismo" y "barbarie" es, como todos sabemos, un error conceptual, histórico, político: el nazismo no fue ciertamente la barbarie sino la exasperación de ese "único orden posible"; pero asimilar "gaucho" y "nazi" no es ya un exabrupto moral, sino una broma de mal gusto. Como siempre con Borges, es necesaria una segunda lectura. Si abrigamos la secreta esperanza de entendernos con su autor, debemos dejar de lado, por un momento las connotaciones éticas del asunto y recordar la operación de la que parte su literatura: el cruce de dos regímenes de legalidad, entre aquel "único orden posible" y esos otros órdenes que lo deslumbran. La Historia Universal de la Infamia, es un examen pormenorizado de esos muchos otros que concluye, justamente, en "Hombre de la esquina rosada" donde es uno de esos otros quien toma la palabra.

Si creemos a Ricardo Piglia - quien afirma que la ficción en la Argentina nace a partir del intento por darle voz al otro - debemos reconocer en aquel libro de Borges la operación que en este texto denuncia como una imposibilidad mental y moral: "jugar a ser el otro". Ese juego 
está atravesado por una justa dosis de horror y fascinación que es el corolario de aquella operación constitutiva. El acento ha de ponerse sin duda en la penúltima frase del párrafo que hemos citado: por esa "irrealidad" que es el nazismo, sin embargo, se mata, se muere, se miente y se tortura.

\section{La Pampa de los Senderos que se Bifurcan}

El segundo texto que hemos de considerar es ya de Fontanarrosa y se titula "La pampa de los senderos que se bifurcan". Es un episodio de Inodoro Pereyra publicado por primera vez en el núm. 38 de Hortensia. En éste, el gaucho de historieta, ayuda al escritor a cruzar la pampa. Leído retrospectivamente, el capítulo anuncia el proyecto que consciente o inconscientemente, Fontanarrosa habrá de seguir en su obra posterior. Hacia el final de la tira, Borges anuncia: "Es inútil, somos un símbolo: Civilización y Barbarie”. La lectura literal, entonces, autoriza desde el principio a considerar la posición del enunciador y autor de la historieta como colocándose en el lugar de la "barbarie", por contraposición a esa cultura letrada que representa Borges. Sin embargo, se puede ser más sutil: ante el reclamo de Mendieta, "lárguelo sólo a este viejo, nos desprecea”, Inodoro replica “déjelo nomás pasar Mendieta, yévese de mi consejo, que yo lo voy a enterrar, cuando se muera de viejo". Inodoro no lo suelta. Sigue cruzando La Pampa junto a Borges. Ya antes, en la primera aparición del gaucho, en el número 25 de Hortensia, se había elegido, para parodiar al Martín Fierro, el episodio borgeano por antonomasia: el momento en que Cruz y Fierro se encuentran, donde el primero se pasa al bando del segundo.

Es decir: el humorista Fontanarrosa, no desecha a ese otro gran humorista que también fue Borges, de alguna manera lo invierte. Por medio del humor (por ejemplo en el Aleph), es que Borges asimila y reescribe la literatura de occidente. A través del humor, Fontanarrosa recupera para la cultura popular y un arte de masas como lo era la historieta, el gesto de Borges y reescribe su literatura (más adelante, él también reescribirá la literatura de occidente, en clave paródica, en Los clásicos según Fontanarrosa). 
Arribemos entonces a las Semblanzas Deportivas, serie que, como se ha indicado, fue en primer lugar publicada en la revista Fierro durante la década del 80, y sólo posteriormente trasladada al libro editado por Ediciones De la Flor en 1989 (más tarde se publicaron más episodios que fueron incluidos en la segunda edición). Un narrador en primera persona, que mira frecuentemente a cámara (es decir, hacia el lector) y que ocasionalmente participa de las historias que relata, nos sumerge en el intrincado mundo del deporte a través de anécdotas de futbol, principalmente, pero también de boxeo, atletismo o de los márgenes del deporte: la lucha libre, las corridas de toros, la ruleta rusa o el futbol infantil.

Ya en su primera aparición en el número 4 de Fierro (diciembre de 1984) se presentaba a la serie, en el editorial, en consonancia con la tradición a la que parodiaba: "el tono evoca la crónica sensiblera — de Borocotó a Caffarelli pasando por Pedrito Valdez el de la 'verde gramilla' - pero también en directa relación con el imaginario al que apelaba 'el futbol es un deporte, un juego, un espectáculo, una pasión de multitudes’ según Muñoz y — pasado por los medios - un lenguaje que ha engendrado la más rica de las mitologías. Es en ese espacio mítico que Fontanarrosa se mueve como mediocampista sin marca". Un espacio mítico: el del deporte, pero también, en el centro, otro imaginario, el de las clases que lo constituyen y el de una violencia desbordante en todos los sentidos. Volveremos sobre esta imagen, la del desborde, que atraviesa todas estas historias.

Juan Carlos "el conejo" Fumetti "centro delantero de la escuadra millonaria" es el protagonista de este primer relato que adopta la forma de la épica del pobre con la que ya en ese entonces se estaba construyendo la figura de Maradona (Alabarces, Peligro de gol. Deporte y..., 134), conjugando a partir de la parodia el espíritu de los tangos "El sueño del pibe" y "Antiguo reloj de cobre".

Pero no es tan sólo eso. La historieta va más allá y pone en primer plano aquello que ni en los tangos ni en el discurso de los medios, ni en la "crónica sensiblera" de aquellas épocas se dejaba entrever: el papel de la hinchada, que hace las veces de espectadora del melodrama en un in crescendo que pasa de la puteada más o menos comprensiva hasta 
las formas más recalcitrantes de la violencia (figura 1). Esta hinchada volverá a aparecer, representada una y otra vez más o menos con los mismos gestos excesivos. Aún en aquella historia donde se busca poner al deporte a salvo de esta clase de exabruptos, "El avance alemán", al que regresaremos más adelante y donde, a pesar de todo, la violencia vuelve a encontrar su camino.

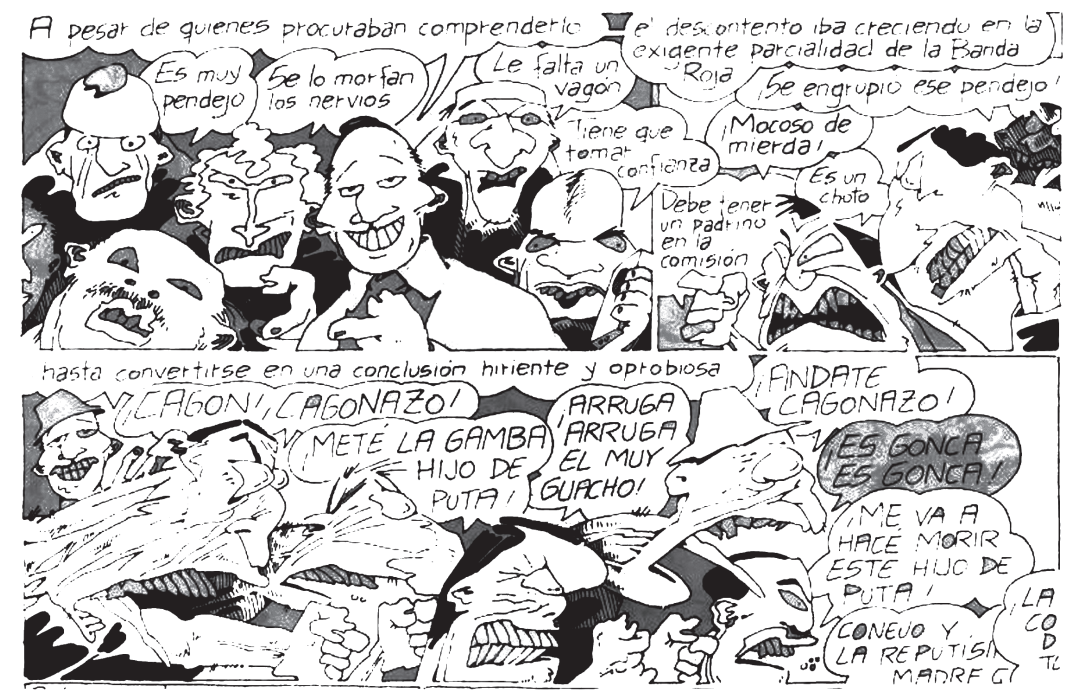

Figura 1: fragmento de la historieta "El Conejo Fumetti" de Fontanarrosa

El desborde pasional con el que se da forma a esa multitud, y en algunos casos, a los mismos deportistas, hiperboliza lo corporal: ojos desorbitados, venas hinchadas, lenguas salidas, sudor, lágrimas, bocas excesivamente abiertas y dientes hacia afuera. Así, el cuadrito donde se celebra el gol que el "pibe" ha hecho (luego de treinta y dos partidos sin anotar) (figura 2) anticipa también el final de la serie Maradoniana: aquella famosa imagen del Mundial de 1994 donde Maradona “imponía, al mismo tiempo, su derecho a un festejo de tinte melodramático - festejaba más que un gol, el regreso de los infiernos tras la suspensión por uso de cocaína- y su dominio, su competencia en las gramáticas televisivas (Alabarces, Peligro de gol. Deporte y..., 151). 


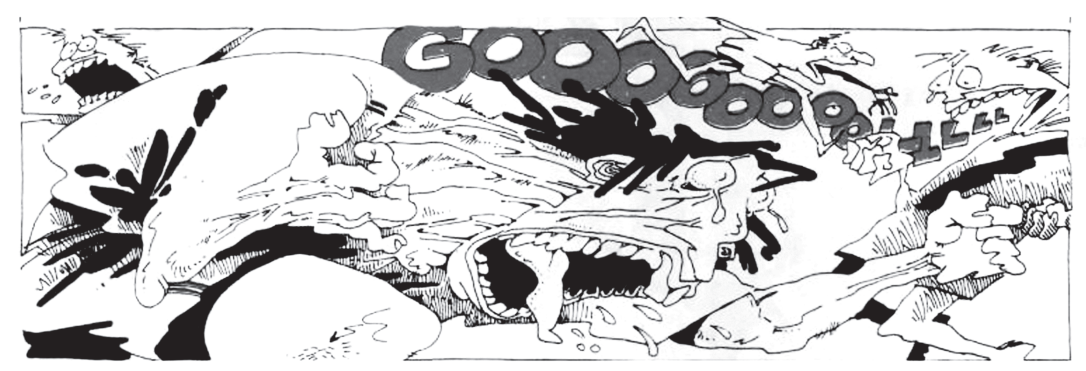

Figura 2: fragmento de la historieta "El Conejo Fumetti” de Fontanarrosa

\section{El cuerpo desaparece. Y otras imágenes del desborde}

Este desborde del cuerpo será otra vez puesto en tensión en "El record de Louven Vogelio" (Fierro, Año 1, número 7, marzo de 1985) donde, se toma literalmente y se hiperboliza el imaginario en torno a los "superatletas" (de los cuales, para la imaginación popular, todavía los futbolistas no participaban), para el cual la tecnología era puesta al servicio del mejoramiento del cuerpo.

En "El record de Louven Vogelio" el deportista es sometido a diversas cirugías y mutilaciones en el afán de alcanzar mayores velocidades. Así le son amputadas las orejas y se le reemplazan los huesos de la pierna "por huesos sin médula, huecos", le sacan las costillas falsas, se le inyectan hormonas de guepardo y finalmente se le amputan ambos brazos. El final no puede ser más significativo: Vogelio, "convertido en una bola de fuego", se pulveriza en el aire. El cuerpo desaparece.

También en "El avance alemán" la tecnología puesta al servicio del futbol se enfrenta a su colmo: los árbitros son reemplazados por una torre de referato, donde éste, junto a sus ayudantes, "lejos del público, aislados del mundo" controlan el juego a través de quince pantallas de televisión, la información de todas las cámaras confluye en una computadora que en fracción de segundo dictamina el fallo. Hacia el final, como podía preverse, los hinchas arrojan un "misil MX-21" sobre la torre "¡Otra vez un MX-21”. "Los hinchas también han progresado en sus protestas" dictamina el personaje que hace las veces de guía.

Pero no es aquí, como podría suceder en otros abordajes al tema, lo tecnológico lo que se pone en cuestión, sino lo humano. La historieta 
deja claro que el misil que arroja la hinchada es el resultado de una mala decisión del árbitro y no de la computadora. Como en Boogie, en cada una de las Semblanzas Deportivas, lo que se pone en juego es un encuentro con lo real en su faceta más siniestra.

Ejemplar en este sentido es el "El extraño caso del Bachacha Fenoglio”, publicado en el núm. 10 de Fierro en mayo de 1985. Otra historia de futbol donde una vez más la hinchada juega un papel fundamental. Aquí el personaje que da nombre a la historia, luego de eludir a sus adversarios en jugadas magistrales, erra los goles. Como se anticipa en el editorial de la revista, lo importante "en el caso del Bachacha Fenoglio -y del país - no es saber por qué no podía jamás hacer un gol sino que-de-una-vez-por-todas lo hiciera". El técnico del equipo aprovecha el impasse de un penal para realizar una sesión de psicoanálisis en pleno estadio en la que determina que el problema del Bachacha se origina en la preadolescencia, donde el grito de gol de su padre interrumpe una promesa de coito con Agostina Belli.

Explicado el problema, ponen a Fenoglio a patear el penal. Pero lo erra. "No era un caso psicológico. Herminio Salomón Fenoglio era un tronco. Un pésimo jugador. Simplemente" Lo cual demuestra que Fontanarrosa tiene un entendimiento más profundo de lo que parece sobre el psicoanálisis. No es que el síntoma se explique por el sueño, sino que el sueño trata de justificar lisa y llanamente el hecho de que Fenoglio juega mal.

Finalmente retorna en "Manuel Linares Socorro 'El horchatas", una vez más, la imagen del desborde ¿Es la tauromaquia un deporte sangriento? La respuesta no puede sino ser excesiva. El protagonista de la historia no muere desangrado por el toro que le perfora la arteria femoral, muere ahogado en sangre, junto con cuatro mil doscientos espectadores "en lo que fue considerado el mayor holocausto causado por un toro en la historia de la lidia". Ese estadio desbordante de sangre, que recuerda el estadio que estalla en El Área 18, autoriza a pensar una vez más, desde la lógica implacable del humor.

\section{La estrategia de Calibán}

Hacia el comienzo de este trabajo nos preguntábamos si el humor negro 
- que es, según hemos querido demostrar, el caso paradigmático del humor, en tanto que la pérdida, lo que se exhibe, es en cierta medida lo que afecta a todos los sujetos, la muerte como real - podría ser calificado de "popular". Hemos contrapuesto el humor a lo cómico, explicando que lo segundo si bien aparenta subvertir las reglas que constituyen la cultura oficial, el discurso hegemónico, en realidad acaba por reconocerlo como el orden dominante. De allí a que todas las formas de lo cómico que se conocen como "populares", de Tinelli a los Midachi, no hacen más que repetir la lógica del poder, sin cuestionarlo. No hacen más que reforzar aquellos estereotipos con que los discursos de las clases dominantes hacen que los subalternos, los dominados, hablen y se piensen a sí mismos.

Pero existe, creemos, la estrategia de Calibán. Ese demonio que grita a Próspero, en la lengua de Próspero, es decir, del colonizador, "Me enseñaste a hablar, y mi provecho es que sé maldecir. ¡La peste roja te lleve por enseñarme tu lengua!". También es posible, para las clases subalternas, maldecir en la lengua del discurso hegemónico. La operación que caracteriza las obras de Fontanarrosa - sin ser, claro está, él mismo un "subalterno" - sobre las que nos hemos detenido, parece reproducir esos mismos estereotipos, pero al llevarlos al extremo, acaba por desmontarlos. Un poco como si dijera: “¿Creen que el futbol, la tauromaquia, el boxeo son deportes violentos? ¡Por supuesto que son violentos! ¡La vida lo es!”.

Por eso podemos decir que Inodoro Pereyra y Boogie, sus personajes más famosos, se colocan en cada polo del espectro: el "gaucho" y el "nazi" de la "Anotación al 23 de agosto de 1944". Y Aunque según Braceli (Fontanarrosa...): "Boogie encarna nuestro deleite carnicero, la religión de la impunidad, la falta de respeto por el vivir de los demás. Pereyra encarna la otra mitad, la de la fanfarronada sin daño, pura espuma, traspasada de ternura"; no podemos más que estar en desacuerdo con esta lectura. Pereyra también mata (por lo menos hasta 1976) y Boogie - según hemos analizado en otro trabajo - encarna más bien frente a los otros (que somos nosotros) el papel de un pedagogo algo drástico que se empeña en desmontar la tontería que atraviesa todos los estratos de eso que llamamos "realidad". No se trata, como en el ejemplo de Freud, de sobreponerse a los "traumas del mundo exterior" 
a través de un gesto de grandeza sino más bien, sin olvidar este gesto, de señalar justamente ese trauma gigantesco que es la realidad, esa herida absurda que es la vida, dicho sea de paso.

\section{REFERENCIAS}

Alabarces, Pablo (comp.), Peligro de gol. Deporte y sociedad en América Latina, Buenos Aires, Consejo Latinoamericano de Ciencias Sociales, 2000.

Alabarces, Pablo, Futbol y patria, Buenos Aires, Prometeo, 2008.

BaJTIn, Mijaíl, La cultura popular en la Edad Media y el Renacimiento, El contexto de Rabelais [1941], Madrid, Alianza, 2003.

Bergson, Henry, La risa. Ensayo sobre el significado de lo cómico, Buenos Aires, Losada, 1991.

Braceli, Rodolfo, Fontanarrosa, Entregate, Buenos Aires, De la Flor, 1992.

Eco, Umberto, "Lo cómico y la regla", en La estrategia de la ilusión, Barcelona, Lumen, 1986.

Freud, Sigmund, "El humor", en Obras Completas. Tomo xxi [1927], Buenos Aires, Amorrortu,1991.

Fontanarrosa, Roberto, El Área 18, Buenos Aires, De la Flor, 1982.

Fontanarrosa, Roberto, "Semblanzas deportivas", Fierro, 4:1, 1984.

Fontanarrosa, Roberto, "Esa energía sublime", Fierro, 6:1, 1985a.

Fontanarrosa, Roberto, "El record de Louven Vogelio", Fierro, 7:1, $1985 \mathrm{~b}$.

Fontanarrosa, Roberto, "El extraño caso del Bachacha Fenoglio", Fierro, 10:1, 1985c.

FontAnarrosa, Roberto, "El avance alemán”, Fierro, 14:2, 1985d.

Fontanarrosa, Roberto, "La desgracia de Juanmiguel Estentóreo", Fierro, $18: 2,1986 a$.

Fontanarrosa, Roberto, "El cazador de ciervos", Fierro, 21:2, $1986 \mathrm{~b}$.

Fontanarrosa, Roberto, "La leyenda del Capirinha”, Fierro, 25:2, 1986c.

Fontanarrosa, Roberto, "El loro de amianto", Fierro, 33:3, 1987.

Fontanarrosa, Roberto, "Los dioses caídos", Fierro, 42:4, 1988.

Fontanarrosa, Roberto, 20 años con Inodoro Pereyra, Buenos Aires, De la Flor, 1998.

Fontanarrosa, Roberto, Todo Boogie, Buenos Aires, De la Flor, 1999.

Fontanarrosa, Roberto, Semblanzas deportivas, Buenos Aires, De la Flor, 2008.

Levín, Florencia, Humor Político en Tiempos de Represión. Clarín 19731983, Buenos Aires, Siglo xxi, 2013. 
Palacios, Cristian, "Notas sobre el humor, lo cómico y los imaginarios nacionales", en Imaginario y nación: episodios, discursos, conceptos, Vázquez Villanueva, Graciana; Burello, Marcelo y Nicolás Bermúdez (ed.), Buenos Aires, Facultad de Filosofía y Letras de la Universidad de Buenos Aires.

Palacios, Cristian. "Boogie en el golfo", en Actas del iv Congreso Internacional de Letras. Transformaciones culturales. Debates de la teoría, de la crítica y la lingüística en el Bicentenario, Buenos Aires, Facultad de Filosofía y Letras de la Universidad de Buenos Aires, 2010.

Piglia, Ricardo, La Argentina en pedazos, Buenos Aires, De la Flor, 1993.

SteImberG, Oscar, "Ahora que pasaron: sobre los homenajes a Fontanarrosa", Crítica. Revista electrónica del área de Crítica de Arte del Instituto Universitario Nacional del Arte, 2:2, Octubre de 2007.

SpIVAK, Gayatri, "Can the subaltern speak?", en Marxism and the Interpretation of Culture, Cary Nelson \& Lawrence Grossberg (eds.), Illinois, Urbana \& Chicago, University UP, 1988, 271-313. 